\title{
Mundo do trabalho, serviço social e desenvolvimento sustentável
}

\section{World of work, social work and sustainable development}

DOI: $10.46814 /$ lajdv2n5-008

Recebimento dos originais: 10/07/2020

Aceitação para publicação: 30/08/2020

\section{Inês Da Silva Moreira}

Doutora em Serviço Social pela Universidade Estadual Paulista Júlio de Mesquita Filho de Franca SP

Endereço: Av. Eufrásia Monteiro Petraglia, 900. Bairro Jardim Santo Antônio Petraglia. CEP 14409160 Franca SP, Brasil

E-mail: inesilva12@gmail.com

\section{Léia Maria Erlich Ruwer}

Doutora em Serviço Social pela Universidade Estadual Paulista Júlio de Mesquita Filho de Franca SP Instituição: Ftec IBGN - Instituto Brasileiro de Gestão e Negócios

Endereço: Avenida Praia de Belas, 1510, CEP 90670-000 Porto Alegre. RS, Brasil

E-mail: leia.rewer@gmail.com

\section{RESUMO}

O presente artigo aborda os temas Trabalho, Serviço Social e Desenvolvimento Sustentável e suas correlações. São temas atuais e de relevância; apresentados de forma a promover reflexões sobre as transformações operadas no domínio do trabalho e suas consequentes repercussões; os desafios postos à sociedade com relação à Sustentabilidade; além de vislumbrar, neste contexto, a participação do Serviço Social, enquanto profissão, com seu caráter sócio-político, crítico e interventivo, que através do instrumental científico e multidisciplinar das Ciências Humanas e Sociais busca intervir nas questões sociais - erradicação da pobreza, equidade social, democracia social e principalmente nos antagonismos entre a produção assalariada e os meios de produção do capital. A pesquisa contempla um estudo bibliográfico e análise das principais referências teóricas dos temas; constituindo caminhos para o enfrentamento destas questões e para a viabilização do desenvolvimento sustentável na vida da sociedade contemporânea, promovida por novos hábitos, novas relações sociais, valores culturais e éticos para um futuro sustentável.

Palavras-chave: Trabalho, Serviço Social, Desenvolvimento Sustentável, Educação Ambiental.

\begin{abstract}
The present article addresses the themes of Work, Social Work and Sustainable Development and their correlations. These are relevant and actual themes; presented in a way to promote reflections on the transformations that have taken place in the field of work and their consequent repercussions; the challenges posed to society in relation to sustainability. In this context, it also glimpses the participation of Social Work as a profession, with its socio-political, critical and intervening character, which through the scientific and multidisciplinary instruments of the Human and Social Sciences seeks to intervene in social issues: eradication of poverty, social equity, social democracy and especially in the antagonisms between wage production and the means of production of capital. The research contemplates a bibliographic study and analysis of the main theoretical references of the themes; establishing paths for the confrontation of these issues and for the viability of sustainable
\end{abstract}


development in the life of contemporary society, promoted by new habits, new social relations, cultural and ethical values for a sustainable future.

Keywords: Work, Social Work, Sustainable development, Environmental Education.

\section{INTRODUÇÃO}

Frente à constatação de que o atual modelo de crescimento econômico gerou desec :11. $^{\text {rios, }}$ na esfera ambiental e social em nível global, vivenciamos, atualmente, um processo constante de debates entre os políticos e a comunidade científica de todo o mundo sobre alternativas de desenvolvimento.

Neste contexto, percebe-se, cada vez mais, como insustentável considerar a dimensão econômica hegemonicamente, uma vez que a mesma apresenta como reflexos:

(...) maior concentração de riqueza, aumento da pobreza, degradação do meio ambiente, utiliza forma predatória de recursos naturais, premia a dimensão material da vida fortalecendo o individualismo e alimentando a visão de curto prazo. Cria, no limite, um cenário favorável para que cada cidadão não se preocupe com as futuras gerações (AMARAL e COSAC, 2009, p.88-89).

O desenvolvimento é um fenômeno complexo, que historicamente resulta de transformações estruturais que, por sua vez, são consequência de movimentos cumulativos de recursos técnicos, materiais e humanos de uma sociedade. E, embora dependa do crescimento econômico, o desenvolvimento não pode ser considerado simplesmente como sinônimo de crescimento econômico, avaliado apenas como um processo de expansão quantitativa do produto e da renda (OLIVEIRA, 1996), e sim como uma transformação qualitativa da sociedade, na mudança de suas características.

Esta perspectiva leva a considerar que o desenvolvimento deve ser analisado de forma interdisciplinar, considerando-se os aspectos sociais, políticos e culturais; e compreendendo o engajamento humano na busca da equidade e justiça social. Isso significa buscar o engajamento de todos os atores sociais na materialização de uma nova forma de desenvolvimento que assegure a permanência e a continuidade das conquistas e avanços na qualidade de vida e na estrutura econômica atual; e, que evite ou minimize as agressões às condições ambientais que tendem a provocar, no futuro, o estrangulamento das possibilidades de desenvolvimento e comprometimento da qualidade de vida da população.

Assim, “(...) só haverá desenvolvimento, que não deve ser confundido com crescimento econômico, quando houver um projeto social subjacente" (FURTADO, 1968, p. 37) e que o mesmo deve ser revestido de um “(...) processo de mudança social e elevação da qualidade das oportunidades da sociedade, compatibilizando, no tempo e no espaço, o crescimento e a eficiência econômicos, a 
conservação ambiental, a qualidade de vida e a equidade social" aliado a uma necessária noção de solidariedade para com as gerações (BUARQUE, 1994, p.17).

Frente a estes desafios postos à sociedade e ao debate apresentado, pode-se vislumbrar participação do Serviço Social, enquanto profissão, com caráter sócio-político, crítico e interventivo, que através do instrumental científico e multidisciplinar das Ciências Humanas e Sociais utiliza instrumentais para intervir nas questões sociais $^{1}$, nos antagonismos entre a produção assalariada e os meios de produção do capital. É uma profissão comprometida com a construção de uma sociedade mais justa, democrática e luta pela garantia dos direitos humanos e universais, fundamentada na Lei 8662-93 que é o código de Ética da profissão e nas diretrizes curriculares de 1993. A partir da década de 1970 e 1980, o Serviço Social passa a ter um projeto ético-político construído pela própria categoria. É uma das poucas profissões que trabalha com projetos profissionais coletivos e com compromissos em várias políticas sociais como: saúde, educação, previdência, habitação, lazer, assistência social, justiça; bem como o foco do presente trabalho - o desenvolvimento sustentável.

A responsabilidade que o profissional do Serviço Social tem para com os problemas do nosso tempo, seja ele de exclusão social ou de natureza ecológica, ou em outras instâncias, passa a exigir dele novas intervenções, que considerem uma sociedade sustentável, ou seja, “(...) aquela que em todos os aspectos da vida cívica e pessoal sejam compatíveis com o desenvolvimento sustentável e todas as instituições públicas, em todos os níveis de governos, trabalhem para avançar esse tipo de sociedade" (UNESCO, 2005, p. 49).

Cabe destacar a importância do papel do profissional de Serviço Social inserido nas mais diversas áreas, executando projetos e programas socioambientais, prestando serviços sociais de forma efetiva; onde o Assistente Social, por meio de sua intervenção, constrói relações entre homens no cotidiano da vida social por meio de ações globais e de cunho socioeducativo.

Assim, interessa-nos no presente texto, abordar o Desenvolvimento Sustentável e a inserção do Serviço Social, enquanto profissão, neste espaço plural, transdisciplinar, complexo e contraditório.

\section{REFERENCIAL TEÓRICO}

\subsection{DESENVOLVIMENTO SUSTENTÁVEL}

Pela complexidade de questões envolvidas, o conceito Desenvolvimento Sustentável encontra-se em fase constante de construção, constituindo pesquisas e discussões de âmbito global e

\footnotetext{
${ }^{1}$ Questões sociais não são senão as expressões do processo de formação e desenvolvimento da classe operária e de seu ingresso no cenário político da sociedade, exigindo seu reconhecimento como classe por parte do empresariado e do Estado. É a manifestação, no cotidiano da vida social, da contradição entre o proletariado e a burguesia, a qual passa a exigir outros tipos de intervenção mais além da caridade e repressão. IAMAMOTO e CARVALHO, (1983, p.77).
} 
local, razão pela qual se revela como alvo de debates, análises e críticas diversas. E, mesmo faltando precisão e conteúdo, cabem-lhe as mais variadas definições (Costa, 2000), além de apresentar um alto grau de adesão e incorporação nos esforços de planejamento e gestão em várias partes do mundo.

A relação entre o crescimento econômico, perdas ambientais e desenvolvimento científico e tecnológico já despertava o interesse dos movimentos ambientalistas das décadas de 60 e 70, o que, aliado aos reclamos da sociedade civil organizada veio a compor uma força crítica aos modelos de desenvolvimento industrial, tanto capitalista, quanto socialista, e despertar uma nova consciência, atenta à dimensão ambiental da realidade. A partir de então a percepção dos problemas ambientais decorrentes do desenvolvimento, ou "mal desenvolvimento", expressão usada por Sachs (1986, p. 94), começa a ser mais efetiva.

A mudança do enfoque na definição da problemática ambiental é salientada por Costa (2000) o enfoque conservador, prevalecente no início dos anos setenta; passa para aquele que busca associar o desenvolvimento econômico à preservação ambiental, à conservação dos recursos naturais e ao aumento da qualidade de vida da população, consagrando assim a ideia de sustentabilidade.

Podem-se identificar marcos histórico-políticos de uma série de iniciativas, e eventos nacionais e internacionais que enfocam a questão do Desenvolvimento Sustentável; como a Conferência Internacional para o Meio Ambiente Humano, promovida pela Organização das Nações Unidas - ONU em 1972 na Suécia; e, no mesmo ano, a publicação do "Relatório Meadows" encomendado pelo Clube de Roma ao Massachusetts Institute of Technology - MIT, com a avaliação da degradação ambiental do planeta e o estabelecimento de previsões futuras. Destaca-se também a Conferência de Estocolmo, com a criação do Programa das Nações Unidas para o Meio Ambiente PNUMA e diversos outros programas com preocupação nos reflexos da industrialização acelerada, na explosão demográfica e na expansão do crescimento urbano, além do cunho ecológico (LIMA, 1997).

Os primeiros princípios de sustentabilidade derivam das bases conceituais do ecodesenvolvimento (1973), formuladas por Ignacy Sachs que são: a) a satisfação das necessidades básicas da população; b) a solidariedade com as gerações futuras; c) a participação da população envolvida; d) a preservação dos recursos naturais e do meio ambiente; a elaboração de um sistema social que garanta emprego, segurança social e respeito a outras culturas, e f) os programas da educação. O conceito de ecodesenvolvimento enfatiza ainda a oposição aos modelos imitativos de crescimento, à importação de tecnologias inadequadas e a promoção da autonomia das populações envolvidas, de forma a superar a dependência cultural a referenciais externos (LIMA, 1997). 
Algumas características estratégicas de desenvolvimento são apresentadas por Cassarotto Filho e Pires (1999):

1. Garantia da sustentabilidade do desenvolvimento: compreensão conjunta do processo em todas as suas dimensões fundamentais (econômica, social, política e ambiental);

2. Visão de longo prazo: análise e planejamento operativo, com ampla visão temporal e capacidade de análise e identificação das prioridades imediatas e futuras; e,

3. Descentralização e participação social: revisão do papel institucional da administração e da representatividade social e os necessários mecanismos que garantam a adesão social (relevância do papel do poder instituído como catalisador e viabilizador das iniciativas sociais, sejam estas privadas ou comunitárias, além do planejamento participativo do esforço de implementação).

O termo Desenvolvimento Sustentável teve suas primeiras referências no Relatório Brundtland, também conhecido como "Nosso Futuro Comum" (Our Common Future), apresentado em abril de 1987 pela Comissão Mundial sobre Meio Ambiente e Desenvolvimento - CMMAD (CMMAD, 1988), e procura sintetizar o Desenvolvimento Sustentável como o processo de desenvolvimento pelo qual são satisfeitas as "necessidades do presente, sem comprometer a capacidade das gerações futuras em satisfazerem as suas próprias necessidades". Parte do pressuposto que exige conciliar o crescimento econômico e a conservação ambiental, como um modo de exploração que leva em conta a solidariedade ambiental e social, respeitando o espaço humano, para somente então considerar o espaço industrial e econômico. Esse conceito traduz o desejo de mudança de paradigma no caminho de um desenvolvimento que não seja socialmente injusto e danoso ao meio ambiente.

O relatório não trata exclusivamente dos problemas ambientais, mas de uma perspectiva relacional centrada nas inter-relações entre estilos de desenvolvimento e seus impactos sobre a natureza, apresentando uma filosofia de desenvolvimento que combina eficiência econômica com prudência ecológica e justiça social, enfatizando a importância da cooperação internacional no enfrentamento dos desafios impostos a toda sociedade (LIMA, 1997)

A característica fundamental do Desenvolvimento Sustentável, de acordo com a CMMAD (1988) é a de não ser estático, e sim um processo de mudança, no qual a exploração de recursos, o gerenciamento dos investimentos, a orientação do desenvolvimento tecnológico e as mudanças institucionais são compatíveis com o futuro, da mesma forma que com as necessidades do presente. 
O Desenvolvimento é sustentável quando está baseado nos seguintes pilares (JARA, 1998): (a) Ecológico: pela conservação dos ecossistemas e pelo manejo racional do meio ambiente e recursos naturais; (b) Econômico: promovendo atividades produtivas razoavelmente rentáveis, preocupadas mais com a qualidade de vida do que com a quantidade de produção, as quais tenham relativa permanência no tempo; e, (c) Social: as atividades e o conteúdo dos processos de desenvolvimento são compatíveis com os valores culturais e com as expectativas das sociedades (existe uma base de consenso entre os atores sociais participantes que permitem controlar as decisões e as ações que afetam seu destino).

Foi a consideração da dimensão social, além da dimensão ambiental inicial, que motivou a definição de novas tendências do Desenvolvimento Sustentável mais voltadas a adotar princípios que contribuam para a melhoria do bem-estar, da ampliação da justiça social e do respeito aos ecossistemas. Seralgedin (1994) interpreta o Desenvolvimento Sustentável como pressuposto para a preservação e melhoria de oportunidades abertas às pessoas de todo o mundo. Segundo este ponto de vista, é de crucial importância mudar a atenção das medidas de fluxo das atividades econômicas para os estoques de recursos naturais, bens produzidos e recursos humanos.

Albuquerque (1996, p.4) complementa que o Desenvolvimento Sustentável, além de se referir à redução do impacto da atividade econômica no meio ambiente, trabalha também com as consequências dessa relação na qualidade de vida e no bem-estar da sociedade, tanto presente quanto futuro:

(...) o desenvolvimento é o resultado do compromisso de uma parte significativa da sociedade local e de mudanças básicas em suas atitudes e comportamentos, o que permite substituir a concepção tradicional de "espaço" (como simples cenário físico) pela de um contexto social de cooperação ativa (um "território").

Silveira (2001) também acredita em ultrapassar a visão da sustentabilidade como preservação de algo que já existe ou como manutenção de práticas pós-imposição de estímulos e, desta forma constituir outros padrões em resposta a insustentabilidade, manifestada pela exclusão social e degradação ambiental.

As propostas elaboradas pelas conferências subsequentes organizadas pela Organização das Nações Unidas, fortificadas pela Agenda 21 da Rio-92 culminam em princípios interdependentes de sustentabilidade a serem considerados como sistemas articulados nas relações Estado-sociedade e nos critérios de eficiência das relações sociais e dos indivíduos com a natureza. Estes critérios foram sintetizados por Sequinel (2002): 
1. Sustentabilidade Ecológica: faz referência à base física do processo de crescimento, com o objetivo de manter estoques de capital natural incorporados às atividades produtivas;

2. Sustentabilidade Ambiental: refere-se à manutenção da capacidade de sustentação dos ecossistemas, e a consequente capacidade de absorção e recomposição dos ecossistemas frente às interferências antrópicas;

3. Sustentabilidade Social: faz referência ao desenvolvimento com base na melhoria da qualidade de vida da população;

4. Sustentabilidade Política: implica no processo de construção da cidadania, e visa incorporar os indivíduos ao processo de desenvolvimento;

5. Sustentabilidade Econômica: implica na gestão eficiente dos recursos e na regularidade de fluxos do investimento público e privado;

6. Sustentabilidade Demográfica: baseia-se nos limites da capacidade de suporte de determinado território e de sua base de recursos, seus cenários e tendências;

7. Sustentabilidade Cultural: refere-se à capacidade de manter a diversidade de culturas, valores e práticas do território;

8. Sustentabilidade Institucional: diz respeito à criação e fortalecimento de engenharias institucionais que considerem os critérios de sustentabilidade; e,

9. Sustentabilidade Espacial: refere-se à busca de maior equidade nas relações inter-regionais.

A partir de então e, sobretudo na última década, as políticas, estratégias e iniciativas de intervenção instituídas pelos diversos setores devem ter, em seu interior, o enfoque do Desenvolvimento Sustentável, aplicado desde o âmbito do planejamento, adotando-se um modo de planejar enfatizando a equidade social, na tentativa de elevar as condições de vida da população, adotando o crescimento econômico como condição fundamental e destacando as condições de preservação ambiental como necessárias (BEZERRA, 2002).

Haddad (2003) expõe que o Desenvolvimento Sustentável da capacidade de organização social e política para modelar o próprio futuro:

O desenvolvimento ocorre quando, na sociedade, se manifesta uma energia capaz de canalizar, de forma convergente, forças que estavam latentes ou dispersas. Uma verdadeira política de desenvolvimento terá que ser a expressão das preocupações e das aspirações dos grupos sociais que tomam consciência de seus problemas e se empenham em resolvê-los. 


\subsection{SERVIÇO SOCIAL}

\subsubsection{Caracterização da profissão}

O Serviço Social surgiu no Brasil na década de 1930, ligado à atuação da Igreja Católica e a serviço de sua ideologia, representando um fruto da ação que a Igreja desenvolveu no campo social de ações caritativas, filantrópicas e de ajuda, devido a interesses da classe dominante pela crescente industrialização brasileira no processo industrial vigente no país. Era uma perspectiva conservadora de controle e legitimação do poder da classe dominante, sob a influência da própria Igreja que reforçava a lógica do capital e onde a atuação do Assistente Social era da mudança comportamental do indivíduo aliada a alterações no meio social.

De acordo com a perspectiva histórica-crítica, o surgimento da profissão de Assistente Social é subproduto dos projetos políticos e econômicos que operavam o desenvolvimento histórico da classe trabalhadora no capitalismo monopolista. Assim, o Estado tomava para si as respostas da questão social enquanto intensificavam-se os conflitos em consequência do desemprego, das precárias condições de vida do trabalhador, o que culminou com o surgimento das políticas sociais como instrumentos de legitimação e consolidação hegemônica da classe dominante - abrindo espaço no mercado de trabalho para o Assistente Social. Este profissional é o responsável por executar tais políticas, por contribuir para o fortalecimento e organização social da classe menos favorecida por melhores condições de vida; lutando pela garantia de seus direitos sociais, e garantindo, por meio de seu exercício profissional, identidade, visibilidade e concreticidade.

O Serviço Social sempre teve como principal empregador o Estado, o qual o contrata para operacionalizar as políticas sociais para trabalhar com as mais diversas expressões da questão social. A conjuntura da época era bastante complexa; sendo que, com a crescente urbanização cresceu também o proletariado, fazendo surgir lutas de reivindicação da classe trabalhadora que se organizavam em contradição com o modelo industrial vigente.

Neste contexto, e como profissão inscrita na divisão do trabalho, o Serviço Social se apresentava como “(...) parte de um movimento social mais amplo, de bases confessionais, articulado à necessidade de formação doutrinária e social do laicato, para uma presença mais ativa na Igreja Católica no mundo temporal, nos inícios da década de 1930 (IAMAMOTO, 1998, p. 18).

Igreja e Estado viviam momentos de tensão e uma questão fundamental para a Igreja no Brasil foi o das relações com o Estado, tendo em vista a separação de ambos desde a Proclamação da República.

No Brasil, as primeiras Escolas de Serviço Social surgiram para que os profissionais trabalhassem com os problemas sociais da época, amenizando conflitos que segundo Lima (1987), 
tinham como foco proteger todos os necessitados, principalmente a classe operária, que não poderia ficar à mercê dos agitadores criminosos.

Neste período, a filosofia usada no Serviço Social era a de Santo Tomás de Aquino que, segundo destaca Mondin (1987, p. 199), apresenta a existência de três espécies de leis para dirigir uma comunidade ao bem-comum: a lei natural, a lei humana e a lei divina. Por decorrência da natureza humana, o homem, por ser um animal social é um "animal político", logo, para que haja o bem-comum é necessário o Estado. Esse Estado supõe autoridade. E, como “(...) toda forma de autoridade deriva de Deus, respeitá-la é respeitar a Deus; toda forma de governo, desde que garanta os direitos da pessoa e o bem-estar da comunidade é boa (...)"; o Estado deve respeitar a Igreja. Desta forma, não existe conflito entre fé e razão; e, se cada um procurar realizar sua tarefa, não há conflito entre Igreja e Estado.

O Serviço Social atuava então frente à "questão social", considerando que “(...) o debate sobre a questão social atravessa toda a sociedade e obriga o Estado, as frações dominantes e a Igreja a se posicionarem diante dela" (IAMAMOTO, 1998, p. 18). Para a Igreja, a "questão social" antes de ser econômica-política, é uma questão moral e religiosa. (IAMAMOTO, 1998, p. 18).

O assistente social convive cotidianamente com as mais amplas expressões da questão social, matéria prima de seu trabalho. Confronta-se com as manifestações mais dramáticas dos processos da questão social no nível dos indivíduos sociais, seja em sua vida individual ou coletiva (ABESS/CEDEPSS, 1996, p. 154-5).

O objeto de intervenção do Serviço Social são as expressões da questão social. A questão social pode ser entendida como conjunto das expressões das desigualdades sociais, segundo Iamamoto (1998, p.27).

O Assistente Social é tido como o executor dos programas e projetos das diversas esferas de governo. Seu trabalho muitas vezes é limitado a cumprir o seu papel institucional, executando apenas programas e projetos para as populações de baixa renda, ou seja, aqueles que vivem em condições de vulnerabilidade social, esperando que este profissional, seja capaz de dar contas de suas necessidades de caráter imediato. Cabe ao profissional estudar detalhadamente as condições de vida do usuário para atendê-lo em sua realidade social.

O exercício do profissional de Serviço Social tem um compromisso e preocupação diante da lei 8.662 de 08 de junho de 1993 que dispõe sobre a profissão de Assistente Social e estabelece sua regulamentação; bem como, em seu artigo $4^{\circ}$ determina as competências do Assistente Social; e, no artigo $5^{\circ}$, as atribuições privativas, como se segue: 
(...) Artigo 5 - Constituem atribuições privativas do assistente social:

I - Coordenar, elaborar, executar, supervisionar e avaliar estudos, pesquisas, planos, programas, e projetos na área de Serviço Social;

II - Planejar, organizar e administrar programas e projetos em Unidade de Serviço Social;

III - assessoria e consultoria a órgãos da administração pública direta e indireta, empresas privadas e outras entidades, em matéria de Serviço Social;

IV - Realizar vistorias, perícias técnicas, laudos periciais, informações e pareceres sobre a matéria de Serviço Social;

V - Assumir, no magistério de Serviço Social tanto em nível de graduação como pósgraduação, disciplinas e funções que exijam conhecimentos próprios e adquiridos em curso de formação regular;

VI - treinamento, avaliação E supervisão direta de estagiários de Serviço Social;

VII - dirigir e coordenar Unidades de Ensino e Cursos de Serviço Social, de graduação e pósgraduação;

VIII - dirigir e coordenar associações, núcleos, centros de estudo e de pesquisa em Serviço Social;

IX - Elaborar provas, presidir e compor bancas de exames e comissões julgadoras de concursos ou outras de seleção para assistentes sociais, ou onde sejam aferidos conhecimentos inerentes ao Serviço Social;

X - Coordenar seminários, encontros, congressos e eventos assemelhados sobre assuntos de Serviço Social;

XI - fiscalizar o exercício profissional através dos Conselhos Federal e Regionais;

XII - dirigir serviços técnicos de Serviço Social em entidades públicas ou privadas;

XIII - ocupar cargos e funções de direção e fiscalização da gestão financeira em órgãos e entidades representativas da categoria profissional (LEI 8.662, 8 jun, 1993)

Destaca-se ainda que, no seu exercício profissional de Assistente Social, é necessário entender o modo de como se realizam suas atividades profissionais.

(...) o assistente social, no exercício de suas atividades vinculados a organismos institucionais estatais, paraestatais ou privados, dedica-se ao planejamento, operacionalização e viabilização de serviços sociais por eles programados para a população (IAMAMOTO e CARVALHO, 1983, p.113).

Essas Leis são importantes para os profissionais de Serviço Social no momento das análises de cada situação apresentadas pelos usuários e também pelas organizações.

\subsubsection{Formação Profissional}

A formação profissional é entendida como um processo dialético, portanto aberto, dinâmico e permanente, incorporando as contradições decorrentes da inserção da profissão e dos profissionais na própria sociedade. Com esse entendimento, falar em formação profissional implica acompanhar a dinâmica da sociedade e a trajetória histórica do próprio Serviço Social, procurando entender os condicionamentos que a sociedade impõe sobre a prática profissional (SILVA, 1984, p.73).

Para abordar a Formação Profissional do Assistente Social é importante compreender como essa profissão tem história, e não pode ser entendida como fato isolado da realidade social. Está se 
expressa num sistema educativo de educação do ensino superior e atua num contexto de sociedade procurando dar resposta a uma demanda social concreta.

As duas primeiras escolas pioneiras do Serviço Social no Brasil foram implantadas em São Paulo (1936) e Rio de Janeiro (1937), durante o governo de Getúlio Vargas, tendo a Igreja Católica como eixo fundamental para sua abertura. O Curso Superior de Serviço Social foi oficializado no país pela Lei $\mathrm{n}^{\circ} 1889$ de 1953. E, em 27 de agosto de 1957, a Lei 3252, juntamente com o Decreto 994 de 15 de maio de 1962, regulamentou a profissão. Assim, para exercer a atividade de Assistente Social, o profissional deve, obrigatoriamente, ser formado em uma Escola de Serviço Social, com formação científica em Serviço Social e com disciplinas científicas - Psicologia, Sociologia, Moral e Biologia. Sua base teórica era de influência europeia tendo como eixo norteador o neotomismo ${ }^{2}$.

$\mathrm{Na}$ época, todo estudo consistia em teorias para adaptar à realidade atual, devendo o profissional possuir formação técnica e específica, consistindo em os estudos das teorias do Serviço Social existente e adaptando à realidade, devendo combater os desajustamentos tanto individuais quanto coletivos. O mesmo atuava mais em relação ao indivíduo e em pequenas comunidades, para adaptá-los a condições de vida social e as suas necessidades.

Quanto à formação pessoal, era de uma escola que se preocupava com a personalidade integral do aluno; devendo possibilitar aos futuros profissionais, uma formação moral e doutrinária, baseada nos princípios cristãos.

Este modelo europeu se fez presente até 1945; a partir de quando ficou estabelecido o modelo norte-americano calcado numa metodologia com pressupostos funcionalistas de cunho positivistas $^{3}$. O método utilizado a partir de então são os métodos de Serviço Social de Caso, de Grupo e de Comunidade; e os objetivos da formação profissional relacionados aos métodos e técnicas. $\mathrm{O}$ atendimento que antes era o da entrevista, observação e questionário; passou a ser realizado com a triagem, os aconselhamentos, o plantão e a distribuição de auxílios.

Tanto o modelo europeu quanto o norte-americano do Serviço Social nessa época eram do Assistente Social se adequar ao sistema político e institucional, o ajustamento do indivíduo a uma sociedade harmônica.

Nos anos de 1950 a 1960, na América Latina, foi expressivo o aumento das Escolas de Serviço Social principalmente no Brasil.

\footnotetext{
${ }^{2}$ Neotomismo, filosofia advinda do pensamento de Santo Tomás de Aquino.

${ }^{3}$ Positivistas, cientistas que multiplicavam a suas descobertas sobre os aspectos da natureza e do homem. Os mais expoentes foram: Saint-Simon e Auguste Comte. Na França, Darwin, Spencer e Stuart Mill na Inglaterra e Heckel na Alemanha e Ardigo na Itália.
} 
(...) através da tecnificação da profissão, preparar o Assistente Social como mão-de-obra capaz de executar programas sociais viabilizadores de soluções modernizantes, necessários à efetivação do modelo desenvolvimentista assumido no Brasil (SILVA, 1984, p.42).

Entretanto, em meados de 1960, parte da categoria profissional começou a ficar insatisfeita e questionar as metodologias, os objetivos, o conteúdo e até a própria linha filosófica utilizada como proposta até aquele momento; levando-os ao Movimento de Reconceituação do Serviço Social.

Os acontecimentos não foram tão rápidos pelo seu desenvolvimento histórico e sua dinâmica social, política e econômica por serem processos evolutivos da própria profissão. Foram muitos os movimentos revolucionários de ordem política onde se questionava o modelo desenvolvimentista urbano industrial e da expansão capitalista vigente.

De 1964 a 1985, o país vivia o período do Regime Militar que imperava no Brasil. Os profissionais do Serviço Social atuavam de forma paternalista e assistencialista, apesar do rigor técnico que se pretendia alcançar.

No final dos anos de 1970 e início de 1980, a crise econômica se agravou, a inflação era rigorosa com índices altíssimos e como se não bastasse, o país estava mergulhado numa extrema dívida externa. É nesse momento que o Movimento de Reconceituação do Serviço Social no Brasil começa sua luta, cobrando do Assistente Social uma postura de caráter mais crítica, mais efetiva, em relação ao que estava acontecendo com a crise mundial e nacional, exigindo uma análise estrutural da realidade e o compromisso com a sociedade. Inicia-se a partir de então, uma formação de caráter crítico-reflexivo, que constrói relações sociais e política.

A década de 90 foi um marco para o Serviço Social, especificamente em 1993, quando foi aprovado o Código de Ética vigente e a Lei de Regulamentação da profissão, objetivando os princípios normativo-legais do projeto ético-político profissional. Neste ano foi aprovada a LOAS Lei Orgânica da Assistência Social, e também a ABEPSS - Associação Brasileira de Ensino e Pesquisa do Serviço Social que deliberou a revisão do currículo mínimo dos cursos de graduação em Serviço Social. Em 1996, constituiu-se também documento intitulado "Proposta básica para o projeto de formação profissional: novos subsídios para o debate". Os pressupostos norteadores da Formação Profissional presente na Revisão Curricular são:

1. O Serviço Social se particulariza nas relações sociais de produção e reprodução da vida social como uma profissão interventiva no âmbito da questão social, expressa pelas contradições do desenvolvimento do capitalismo monopolista.

2. A relação do Serviço Social com a questão social - fundamento básico de sua existência - é mediatizada por um conjunto de processos sócio históricos e teórico-metodológicos constitutivos de seu processo de trabalho.

3. O agravamento da questão social em face das particularidades do processo de reestruturação produtiva no Brasil, nos marcos da ideologia neoliberal, determina uma inflexão no campo 
profissional do Serviço Social. Esta inflexão é resultante de novas requisições postas pelo reordena mento do capital e do trabalho, pela reforma do Estado e pelo movimento de organização das classes trabalhadoras, com amplas repercussões no mercado profissional de trabalho.

4. O processo de trabalho no Serviço Social é determinado por configurações estruturais e conjunturais da questão social, e pelas configurações estruturais e conjunturais da questão social e pelas formas históricas de seu enfrentamento, permeadas pela ação dos trabalhadores, do capital e do Estado, através das políticas e lutas sociais (ABESS, 1997, p.60).

Tem-se, assim, que o perfil do profissional pretendido. Um assistente social capacitado para ações qualificadas no plano teórico - metodológico prático - operativo e ético-político. Estes pressupostos apontam para as diretrizes curriculares que dão sustentação a uma formação profissional que possibilite a:

$\checkmark$ Apreensão crítica do processo histórico como totalidade;

$\checkmark$ Investigação sobre a formação histórica e os processos sociais contemporâneos que conformam a sociedade brasileira, no sentido de apreender as particularidades da constituição e desenvolvimento do capitalismo e do Serviço Social no País;

$\checkmark$ Apreensão do significado social da profissão desvelando as possibilidades de ação contidas na realidade;

$\checkmark$ Apreensão das demandas - consolidadas e emergentes - postas ao Serviço Social via mercado de trabalho, visando a formular respostas profissionais que potenciem o enfrentamento da questão social, considerando as novas articulações entre público e privado; e,

$\checkmark$ Exercício profissional cumprindo as competências e atribuições previstas na Legislação Profissional em vigor (ABESS, 1997, p.62).

Procurou-se então, manter o caráter generalista da formação profissional, no plano institucional, como um requisito a mais, exigido pelo mercado de trabalho.

No sentido de garantir o perfil pretendido e atingir os objetivos do curso, entende-se a importância de um conjunto de conhecimentos indissociáveis, que se traduz em Núcleos de fundamentação constitutivos da formação profissional, que são:

1. Núcleo de fundamentos teórico-metodológicos da vida social: Responsável pela compreensão e explicitação teórico - analítica dos aspectos individuais, relações e fatos sociais (micro e macro abordagens) e das realidades sociais, em seu sentido histórico e contemporâneo. Tratam da compreensão do desenvolvimento da sociedade atual em seus aspectos econômicos, sociais, políticos, filosóficos e culturais; os fenômenos e manifestações institucionais, culturais e sua relação com o fundamento da ação profissional. 
2. Núcleo de fundamentos sócio histórica da sociedade brasileira: Conhecimento da constituição econômica, social, política e cultural da sociedade brasileira, em sua situação dependente, urbano-industrial, na diversidade regional e local, questão agrária e agrícola. Devem ser objetos de estudo e análise: os padrões de produção capitalista brasileira nos diferentes modelos de gestão e organização do processo de trabalho, suas consequências culturais e sociais, tanto individuais como grupais e de segmentos de classe, sendo o eixo condutor da ordenação dos conteúdos a questão social e os fenômenos de exclusão. Dentro deste núcleo, a constituição do Estado brasileiro - caráter, papel, trajetória, organização e vínculos - e os diferentes projetos políticos e societários existentes na sociedade brasileira: fundamentos, princípios, análise de sociedade, estratégias e programáticas das classes em confronto. O significado do Serviço Social no Brasil e sua construção histórica no jogo das dinâmicas institucionais e organizacionais integram também o conteúdo deste Núcleo.

3. Núcleo de fundamentos de trabalho profissional: A profissionalização do Serviço Social como uma especialização do trabalho e sua prática como concretização de um processo que tem como objeto as diferentes e múltiplas expressões da questão social e das necessidades sociais. O processo de trabalho no Serviço Social exige, portanto, a definição de objetos, objetivos, instrumentos e técnicas de atuação, além de referências teóricas - metodológicas que dão sustentação aos elementos indicados. Em relação ao Serviço Social, a sua finalidade maior, na realidade brasileira em um plano ético, é a defesa dos direitos sociais, a ampliação da cidadania. A concretização de tais finalidades implica, no entanto, na realização de ações concretas viabilizadas através dos serviços prestados à população usuária.

Esses três núcleos articulam conteúdos necessários para compreender o processo de trabalho do Assistente Social. São eixos articuladores da formação profissional que se pretende; e, somente a partir desta compreensão é que se poderá construir e implementar estratégias e técnicas de intervenção a partir de quatro questões: por que fazer (dimensão intelectiva); o que e como fazer (dimensão operativa); para que (dimensão ontológica).

Esses núcleos são considerados como indissociáveis entre si em uma relação de horizontalidade entre os mesmos, expressando “(...) níveis diferenciados de apreensão da realidade social e profissional, subsidiando a intervenção do Serviço Social” (ABESS/CEDEPSS, 1997, p. 64$65)$.

A partir de 1994, muitas mudanças ocorreram nas Unidades de Ensino Superior de Serviço Social. Em 20 de dezembro de 1996 foi promulgada a LDB - Lei das Diretrizes Básicas - (9394), 
onde o Curso de Serviço Social passa a estabelecer diretrizes a partir dessa nova Lei, assegurando a flexibilidade e descentralização do ensino em Serviço Social de modo a acompanhar as profundas transformações da ciência e da tecnologia contemporânea.

De acordo com o Caderno ABESS:

Os novos perfis assumidos pela questão social frente a reforma do Estado e às mudanças no âmbito da produção requerem novas demandas de qualificação do profissional, alteram o espaço ocupacional do Assistente Social, exigindo que o ensino superior estabeleça padrões de qualidade adequados (ABESS, 1996, p. 59).

Segundo o Conselho Nacional de Educação (CNE) de 2001, “As novas diretrizes curriculares para o Curso de Serviço Social”, não são mais como currículo mínimo obrigatório, pois o ensino da prática é retomado juntamente com a pesquisa e a ética de acordo com a ABESS/CEDEPSS (1996). A competência profissional passa a englobar as dimensões de intervenção profissional - teórico metodológica, ético-política e técnico-operativa; tendo como eixo central a “questão social” nas suas determinações sócio históricas e ideo-políticas.

A preocupação do Serviço Social é de construir, a partir desse momento:

Uma proposta de formação profissional conciliada com novos tempos, radicalmente comprometida com os novos valores democráticos e com a prática de construção de uma nova cidadania na vida social, isto é, de um novo ordenamento das relações sociais (IAMAMOTO, 2005, p. 168).

Assim, pode-se entender Formação Profissional do Assistente Social como um amplo processo de uma formação social, que abrange desde a formação acadêmica (graduação e pósgraduação), até a capacitação continuada, a prática interventiva, e a pesquisa que se expressa num vínculo com a sociedade.

O Serviço Social como profissão configura-se com um projeto ético-político profissional a partir dos anos de 1980 e 1990 na sociedade brasileira, com uma formação capaz de inserir-se criticamente no conjunto das relações sociais e no mercado de trabalho. O profissional tem perfil de conhecer o movimento histórico da sociedade brasileira, as particularidades do desenvolvimento do capitalismo, a formulação e implementação de propostas profissionais e enfrentamento das "questões sociais", assim como pesquisa sobre a realidade social. Além de capacitar para exercer a docência para a formação profissional específica do Assistente Social.

$\mathrm{Na}$ perspectiva do presente trabalho, destaca-se que muitos estudos acadêmicos e pesquisas estão sendo desenvolvidos e discutidos com temas relacionados ao Desenvolvimento Sustentável, meio ambiente, responsabilidade ambiental e questão ambiental, nos mais diversos segmentos da 
sociedade - o que pressupõe a participação do Assistente Social. Considerando-se que o Serviço Social no Brasil tem o compromisso acadêmico de trabalhar eixos como este na sociedade, devido a sua longa trajetória de intervenção e compromisso com as questões sociais. E o Desenvolvimento Sustentável não pode ser área específica de nenhuma especialidade do conhecimento do homem; uma vez que é um saber construído socialmente envolvendo todas as áreas do conhecimento.

\section{INTERVENÇÃO DO PROFISSIONAL DO SERVIÇO SOCIAL NO DESENVOLVIMENTO SUSTENTÁVEL}

O Serviço Social encontra-se relacionado ao desenvolvimento sustentável, uma vez que o Desenvolvimento Sustentável está presente no contexto ambiental e configura-se como uma das múltiplas expressões da questão social; e, assim, objeto de trabalho do Serviço Social.

Nesta perspectiva, abordar o meio ambiente, desenvolvimento sustentável e sustentabilidade, é também abordar o papel do ser humano, da natureza, das relações sociais. Isso pode ser realizado por meio de intervenções que possibilitem uma consciência crítica com ações direcionadas e revestidas pela ética e responsabilidade.

Neste sentido, e pelas considerações teóricas abordadas até este momento, é fato que os assistentes sociais por longa data vêm trabalhando com as camadas excluídas e marginalizadas da sociedade; e, reúnem a experiência acumulada necessária para a atuação no Desenvolvimento Sustentável. O seu trabalho profissional tem um histórico não só de intervenção, mas de educação política e social, incentivando as pessoas para a construção de uma sociedade sustentável e justa.

O Assistente Social terá grande contribuição no Desenvolvimento Sustentável, quando prepara cidadãos para uma reflexão crítica e reflexiva; e, consequentemente, para uma ação social corretiva e transformadora no seu âmbito de inserção.

A Educação Ambiental também se apresenta nesta perspectiva, aliada ao Desenvolvimento Sustentável, contrária ao sistema capitalista atual ou ao desenvolvimento econômico vivenciado pela sociedade atualmente. Pois, os valores de justiça social, éticos e de solidariedade não são considerados quando o lucro, a competição os privilégios são colocados em detrimento a nossa sociedade. E o Serviço Social tem grande conhecimento sobre o sistema e entende que os problemas socioeconômicos, culturais e políticos, são os geradores dos estragos ambientais.

(...) percebemos também a tentativa de se discutir e construir outra identidade para os/as assistentes sociais profundamente relacionada com a perspectiva de educadores ambientais. [...] A aproximação dos/das assistentes sociais com o campo da educação ambiental não só é bem-vinda, como também, é necessária a pertinente. Entre nós, educadores ambientais, os/as assistentes sociais poderão ter contato e dialogar com um conhecimento socioambiental 
específico, diferentes tipos de intervenção e um acúmulo de argumentos e experiências pedagógicas consideráveis (REIGOTA, 1994, p.8)

A contribuição que o profissional de Serviço Social traz ao longo de sua profissão quando desempenha suas atribuições como um interventor, através das relações socioeconômicas é bastante significativa. Também será de extrema importância desempenhar um papel de educador ambiental, pois a necessidade de integrar o social com o ecológico é relevante para garantir um planeta mais saudável.

O Serviço Social tem características para desenvolver o papel de educador ambiental, de acordo com o Informativo do CRESS/SP n.14:

\begin{abstract}
A preservação do Meio Ambiente é um tema relacionado ao trabalho do meio ambiente. É um tema relacionado ao trabalho do Assistente Social, uma vez que a garantia da qualidade de vida e dos direitos básicos das populações depende diretamente da qualidade do meio ambiente em que elas estão inseridas. É o caso, por exemplo, das comunidades situadas próximas a mananciais e áreas de preservação. Cabe ao Serviço Social, em trabalhos com populações residentes nessas regiões, articulá-las na luta pela garantia do direito à moradia, pela preservação ambiental e pelo desenvolvimento sustentado, respeitando as especificidades das culturas locais afirma Margarida Maria de Almeida Motta, da área de Controle Ambiental da Secretaria Municipal do Verde e Meio Ambiente de São Paulo (CRESS/SP, 2003, p. 1).
\end{abstract}

O assistente social é capaz de provocar uma mediação, proporcionando diálogo e reflexão enquanto ação educativa no campo social e ambiental. Suas intervenções são voltadas para um trabalho de conscientização, educação e cidadania na sociedade, pois a cidadania é um interesse comum na consciência e no exercício dos direitos e deveres descritos na legislação. Em ações que buscam, afinal:

\footnotetext{
Uma educação para promover um pensamento sistêmico, global, de que as coisas não ocorrem de forma isolada, nem se devem a uma só causa. Uma educação que ajude a tomar consciência da complexidade da questão ambiental não apenas em sua origem, mas em sua resolução. Uma educação que leve nosso pensamento e ação a pensar globalmente e agir localmente, que ajude a refletir sobre a amplitude das repercussões de nosso modo de vida para além do âmbito local em que nos relacionamos (GÓMEZ, AGUADO e PEREZ, 2005, p.34).
}

Sua reflexão é de uma educação que leva as pessoas a tomar consciência enquanto pessoa humana e a necessidade de assumir a responsabilidade e o compromisso com a preservação do meio ambiente.

Cabe ao profissional de Serviço Social, juntamente com o poder público e a população, potencializar uma articulação com os governos locais para o desenvolvimento de práticas educativas e na preservação do meio ambiente. 
Educar para a cidadania responsável vai exigir do profissional de Serviço Social uma consciência crítica, reflexiva e criar estratégias para habilitar grupos para uma ação social comprometida em preparar cidadãos para a participação social, contribuição e formulação de políticas voltadas para o bem-estar, ou mesmo, para a saúde de nosso Planeta e porque não em uma cultura democrática. A população menos favorecida tem sofrido os impactos ambientais pela falta de água, energia, alimentação,

Assim, a sociedade civil juntamente com os órgãos públicos, devem ser fortalecidos e incentivados para legitimar esse processo de descentralização na gerência dos recursos e ações do governo.

A educação não formal, por sua vez, deve buscar desenvolver a sensibilidade da coletividade para a resolução das questões ambientais, estimular sua organização e participação na construção de políticas públicas saudáveis e na defesa da qualidade do meio ambiente (PELICIONI, 2002, p.347).

Reigota afirma sobre a educação não-formal que:

O desafio de uma cidadania ativa se configura como elemento determinante para constituição e fortalecimento de sujeitos cidadãos que conscientes de seus direitos e deveres, assumam a importância da abertura de novos espaços de participação (REIGOTA, 1994, p.33).

E a participação da sociedade só se dará por meio de uma educação socioambiental, possibilitando às pessoas conhecer valores, conhecimentos, novas maneiras de pensar e ser, estabelecendo uma relação de ética e compromisso com as causas dos problemas ambientais.

Assim, para que haja uma mudança no comportamento da sociedade em relação ao uso dos recursos naturais de forma a proteger o meio ambiente, é necessário um exercício de cidadania ativa, no fortalecimento dos sujeitos para assumirem a missão de participar na preservação do nosso planeta.

\section{CONSIDERAÇÕES FINAIS}

O presente estudo, não pretende esgotar a temática sobre o assunto, até porque a Formação Profissional e o Desenvolvimento Sustentável estão em constantes mudanças. As reflexões tecidas acerca do início do desenvolvimento do Serviço Social foram importantes para conhecer e aprofundar o tema formação acadêmica do Assistente Social.

Os inúmeros desafios relativos ao Desenvolvimento Sustentável se apresentam como novas expressões da questão social; e, desta forma, constituem também, objeto da profissão do Serviço Social, uma vez que, como novas expressões, um dos caminhos de enfrentamento é a introdução do 
desenvolvimento sustentável na vida da sociedade contemporânea, promovida por novos hábitos e novas também relações sociais.

Para que isto se viabilize, no entanto, faz-se necessário criar condições nos aspectos políticos, ambientais, sociais e econômicos, uma vez que a sociedade sofre influências e reflexos da globalização e direcionamento do capitalismo, que estimula uma forma de consumo exacerbado.

Neste sentido, cumpre destacar novamente, a diferença entre crescimento e desenvolvimento, uma vez que o primeiro não conduz à igualdade, muito menos à justiça social, uma vez que considera apenas o acúmulo de riquezas. Já o segundo se preocupa também com a geração de riquezas, mas com aspecto qualitativo, uma vez que se reveste do o objetivo de distribuí-las na perspectiva de melhorar a vida da população, considerando a qualidade e o equilíbrio do planeta.

A globalização da economia e o capitalismo crescem acentuadamente, reproduzindo a questão social que demonstra evidência entre o crescimento das forças produtivas do trabalho social e as relações sociais. Os reflexos traduzem-se na banalização da vida humana, na violência por de traz do capital; e, tem a proteção do Estado que se coloca a serviço dos que dominam o sistema social, político e econômico.

A política social analisada à luz das imposições da política econômica reduz os gastos públicos, e com isto o atendimento aos programas sociais fica focado e fragmentado, não atendendo de forma equitativa a milhões de pessoas que vivem em condições subumanas.

A sociedade pouco se deu conta de que o consumismo tem diminuído a qualidade de vida das pessoas e destruindo a natureza. Padrões de consumo e de produção alteraram a natureza de muitas maneiras, ao construir cidades e impermeabilizar o solo; ao destruir desordenadamente florestas para plantar ou criar gado; ao explorar riquezas minerais, dentre outros. Como se não bastasse, é comum o depósito de lixo, entulho, que ao mesmo tempo em que degradam o solo, contaminam em conjunto mananciais, além do próprio ar.

As alternativas do Desenvolvimento Sustentável almejadas envolvem, necessariamente, práticas sustentáveis; as quais, por sua vez, encontram dificuldades inúmeras para se desenvolver. Elas não se concretizam sem a adoção e o investimento de políticas públicas que possam gerar emprego, segurança, educação e saúde; além de políticas ambientais, voltadas para o desenvolvimento social sustentável.

Também o Serviço Social está presente no arcabouço dessa transformação e construção de uma consciência nova a partir da educação social. 


\section{REFERENCIAS}

ABESS, Cadernos ABESS (1996), Formação Profissional: Trajetórias e Desafios, No. 7 Novembro de 1997, Cortez Ed.Especial: São Paulo, 1996.

/CEDEPSS. Diretrizes gerais para o curso de Serviço Social. Cadernos ABESS. No 7, Cortez Ed. Ed. Especial: São Paulo, 1997.

ABEPSS (2000), Reforma do Ensino Superior e Serviço Social. Revista TEMPORALIS, Ano I, No 1 - janeiro a junho de 2000, Brasília, 2000.

ALBUQUERQUE, Francisco. Desenvolvimento e fomento produtivo local para superar a pobreza. Tradução do trabalho "Desenvolvimento e fomento produtivo local para a superação da pobreza no Chile", apresentado pelo autor no seminário de mesmo nome organizado pelo Fundo de Solidariedade e Investimento Social e pelo Ministério de Planejamento e Cooperação (FOSIS/MIDEPLAN), conjuntamente com o ILPES, realizado na sede da CEPAL em 12 e 13 de ago.1996.

Disponível

em:

$<$ http://www.rededlis.org.br/textos_download.asp?action=lista\&ordena=titulo $>$. Acesso em: 18 ago. 2003.

AMARAL, R.G.; COSAC, C.M.D.. O Terceiro Setor e o Desenvolvimento Sustentável. In.: SERVIÇO SOCIAL \& REALIDADE (Faculdade de História, Direito e Serviço Social - UNESP) v. 18, n.2. UNESP: Franca, 2009.

BEZERRA, Maria L. Desenvolvimento Urbano Sustentável: realidade ou utopia. Fundação Joaquim Nabuco, 2002. Disponível em 〈http://www.fundaj.gov.br/tpd/140.html>. Acesso em 16 ago. 2002.

BUARQUE, Sérgio C. Metodologia de planejamento do Desenvolvimento Sustentável. IICA: Recife, 1994.

CASSAROTTO FILHO, N.; PIRES, L.H.. Redes de pequenas e médias empresas e Desenvolvimento Local: estratégias para a conquista da competitividade global com base na experiência italiana. Atlas: São Paulo, 1999.

CMMAD/ONU - Comissão Mundial de Meio Ambiente e Desenvolvimento da Organização das Nações Unidas. Nosso Futuro Comum. FGV: Rio de Janeiro, 1988.

COSTA, Heloísa Soares M.. Desenvolvimento urbano sustentável: uma contradição de termos? Revista Brasileira de Estudos Urbanos e Regionais, Recife, n.2, p.55-72, mar. 2000.

DORNELES, Denise Freitas. A prática do Assistente Social em uma comunidade sustentável: Desafios para a sociedade contemporânea. Tese de Doutorado - Faculdade de Serviço Social, TEMPORALIS, Ano I, No 1 - janeiro a junho de 2000, Brasília.

FURTADO, Celso. Um Projeto para o Brasil. Saga: Rio de Janeiro, 1968.

GOMEZ, J. A. D. AGUADO, O. V. PÉREZ, A. G. (Orgs.). REIGOTA, M. Prefácio. Serviço Social e meio ambiente. São Paulo: Cortez, 2005.

HADDAD, Paulo Roberto. Agenda 21 Brasileira - versão preliminar. Comissão de Políticas de Desenvolvimento Sustentável e da Agenda 21 Nacional. Secretaria Executiva, Fev. 2002. 
desenvolvimento

- A organização dos sistemas produtivos 〈http://www.iadb.org/foromic/Vforo/downloads/Haddad.doc. >. Acesso em 03 mar. 2003.

IAMAMOTO, M. V.; CARVALHO, R. Relações sociais e Serviço Social no Brasil. São Paulo: Cortez/Celats, 1983.

IAMAMOTO, M.V. Renovação e Conservadorismo no Serviço Social. São Paulo: Cortez, 1992. . O Serviço Social na Contemporaneidade. São Paulo: Cortez, 1998. .O Serviço Social na Contemporaneidade. São Paulo: Cortez, 2005.

INFORMATIVO CRESS/SP (2003) n.14. Disponível em: http://www.cress-sp.org.br. Acesso em 09 de fevereiro de 2010.

JARA, C. J.. A sustentabilidade do Desenvolvimento Local: desafios de um processo em construção. Recife: SEPLAN,1998.

LEI 3.252, de 27 de agosto de 1957. http://www.jusbrasil.com.br/legislacao/128729/lei-3252-57. Acesso em 09 de fevereiro de 2010.

LEI 8.662, de 8 de junho de 1993. Disponível em: http://www.cresspa.org.br/files/u4/01_Lei_8662.pdf. Acesso em 09 de fevereiro de 2010.

LIMA, A. A. Serviço Social no Brasil: ideologia de uma década. 3 ed. São Paulo: Cortez, 1987.

LIMA, Gustavo F. Da Costa. O debate da sustentabilidade na sociedade insustentável. Política $e$ Trabalho. João Pessoa, n. 13, p.201-222, Set/1997.

MONDIN, B. Introdução à Filosofia. São Paulo: Paulinas, 1987.

OLIVEIRA, Pérsio Santos de. Introdução à sociologia. 16. e. São Paulo: Ática, 1996.

PELICIONI, M. C. F., Philipi Jr. A. Meio ambiente, direito e cidadania: uma interação necessária. In. Philippi Jr. A., ALVES, A. C., ROMERO, M. A., BRUNA G. C., Editores. Meio ambiente, direito e cidadania. São Paulo: Signus, 2002. P.347-51.

REIGOTA, M. O que é educação ambiental? São Paulo: Cortez, 1994.

RESOLUÇÃO CNE/CES No 1, DE 3 DE ABRIL DE 2001. Disponível em: $<$ http://portal.mec.gov.br/seed/arquivos/pdf/tvescola/leis/CES0101.pdf. Acesso em 09 de fevereiro de 2010.

SACHS, I. Ecodesenvolvimento: crescer sem destruir. São Paulo: Vértice, 1986.

SEQUINEL, Maria C. M. O modelo de Sustentabilidade Urbana de Curitiba, um estudo de caso. Florianópolis, 2002. 108 p. Dissertação (Mestrado em Engenharia de Produção) - Universidade Federal de Santa Catarina, UFSC.

SERALGEDIN, Ismail (ed.) Environmental Development Sustainable: from concepts to Action. THE WORLD BANK, 1994.

SILVA, M. O. S. Formação Profissional do Assistente Social. São Paulo: Cortez, 1984. 
SILVEIRA, Caio Márcio. Miradas, Métodos, Redes: o Desenvolvimento Local em curso. In: SILVEIRA, Caio Márcio; COSTA REIS, Liliane da (orgs). Desenvolvimento Local: dinâmicas $e$ estratégias. Rio de Janeiro: RITZ, 2001.

UNESCO. Década das Nações Unidas da Educação para o Desenvolvimento Sustentável, 20052014. Documento final do plano internacional de implementação. Brasília: UNESCO, Orealc, 2005. PUC/RS, 2005. 